\title{
Cortical Auditory Evoked Potentials in 2-Year-Old Subjects
}

\author{
Inaê Costa10 Ayra Renata D’Agostini ${ }^{1}$ Jennifer Alves Sousa ${ }^{1}$ Ana Paula Ramos de Souza ${ }^{1}$ \\ Eliara Pinto Vieira Biaggio ${ }^{1}$ \\ ${ }^{1}$ Department of Speech Pathology, Universidade Federal de Santa \\ Maria, Santa Maria, RS, Brazil \\ Int Arch Otorhinolaryngol 2020;24(3):e282-e287. \\ Address for correspondence Inaê Costa, PhD, Department of Speech \\ Pathology, Federal University of Santa Maria, Rua Silva Jardim, 1067, \\ Centro, Postal Code: 97010-491, Santa Maria/RS, Brazil \\ (e-mail: inaecost@gmail.com).
}

\begin{abstract}
Keywords

- auditory perception

- child

- evoked potential

- maturation

- electrophysiology
\end{abstract}

\section{Introduction}

Auditory evoked potentials (AEPs) measure the electrical activity generated at several levels of the nervous system in response to acoustic stimuli. ${ }^{1,2}$ Auditory evoked potentials are classified based on their latency into the following categories: brainstem auditory evoked potentials (BAEPs) have a latency of 0 to $10 \mathrm{~ms}$, and consist of short latency potentials which travel from the auditory nerves to the brainstem; Middle-Latency Auditory Evoked Potentials (MLAEPs) have a latency of 10 to $80 \mathrm{~ms}$; and Long Latency Auditory Evoked Potentials (LLAEPs) occur 80 to $600 \mathrm{~ms}$ after exposure to the stimulus, and are generated by the bioelectrical activity of thalamocortical neurons. ${ }^{3}$

In neonates and infants, the study of AEPs contributes to the assessment of the sensitivity, maturation, and neuroplasticity of auditory pathways, consisting an important source of information on auditory processing and the potential need of sound amplification, facilitating the implementation of early intervention programs, if necessary. ${ }^{4-8}$

Cortical auditory evoked potentials (CAEPs) are longlatency responses also known as exogenous potentials, since they are determined by the physical properties of the stimulus rather than by the response of the subject. Cortical received

May 18, 2019

accepted

September 17, 2019

published online

December 13, 2019
DOI https://doi.org/

10.1055/s-0039-1700585. ISSN 1809-9777.
Copyright (e 2020 by Thieme Revinter

Publicações Ltda, Rio de Janeiro, Brazil
License terms

()ㅇㅇ $\Theta \circledast$ 
auditory evoked potentials consist of a series of waves (P1, $\mathrm{N} 1, \mathrm{P} 2$ and N2) of varying amplitude, latency and polarity. The waves can be either positive $(\mathrm{P})$ or negative $(\mathrm{N})$ and tend to occur 50 to $300 \mathrm{~ms}$ after the onset of the stimulus. These waves signal the arrival of the stimulus at the auditory cortex, and therefore contribute to the assessment of functional sensitivity and auditory thresholds. ${ }^{1}$

Cortical auditory evoked potentials reflect the detection of the stimulus by the auditory system. This process depends on the maturation of auditory pathways connecting peripheral structures to the auditory cortex ${ }^{9}$ and precedes the acquisition of more complex auditory and cognitive skills, and is therefore crucial for speech and language development. ${ }^{10}$ Cortical auditory evoked potentials are also considered a biomarker of auditory maturity. Exogenous potentials decrease in latency and increase in amplitude during the $1^{\text {st }}$ year of life, reaching full maturity at $\sim 14$ years old, ${ }^{5,11,12}$ although they may continue to change well into the $2^{\text {nd }}$ decade of life. ${ }^{13}$

At birth, it is possible to detect the presence of the components $\mathrm{P} 1 / \mathrm{N} 1 ;{ }^{14,15}$ however, the age at which the other components of the CAEP arise is not yet precisely known. ${ }^{16}$ The changes in these components are related to the age that they reflect in the maturation of the neural processes generating the response.

Auditory maturation depends on several internal and external factors, including exposure to auditory stimulation, individual differences in developmental rates, as well as the integrity of the auditory system. ${ }^{17}$ There is no consensus in the literature regarding the age at which different components of LLAEPs first appear, or the age-based reference values for signal latency, ${ }^{17}$ although studies on the topic have been conducted. 4,5,7-9,11,12,14,18-31

To date, no studies appear to have investigated CAEPs using verbal stimuli and the Smart EP platform (Intelligent Hearing Systems, Miami, FL, USA) in 2-year-old subjects. We hypothesized that $\mathrm{P} 2$ and $\mathrm{N} 2$ waves would be present by the age of 2 years old, since the level of myelination of the auditory cortex at this age would allow for the emergence of these components of the CAEP. The aim of the present study was to determine the presence, latency and amplitude of CAEP components in response to verbal stimuli in children aged 2 years old.

\section{Method}

This was a prospective, quantitative study conducted as part of a postdoctoral fellowship (PNPD-CAPES). This protocol was approved by a university research ethics committee (protocol number CAAE: 28586914.0.0000.5346.). All of the procedures were conducted in accordance with the ethical recommendations of National Health Resolution 466/2012. Researchers signed a confidentiality agreement, while the parents or guardians of the participants provided written consent to the participation of their children in the study.

The sample consisted of 2-year-olds, born at term, seen at the Neonatal Auditory Screening service of a public health center, where the subjects underwent a transient otoacous- tic emissions test, when they did not present a risk indicator for hearing impairment (to affirm the integrity of outer hair cells, and therefore, assure normal cochlear function) and/or Automatic Auditory Brainstem Response evaluation (hearing threshold of $35 \mathrm{dBnHL}$ in both ears, confirming the integrity of auditory pathways in the brainstem, in children, present a risk indicator for hearing impairment as hyperbilirubinemia, syndromes, congenital infections and others), following the international protocol of the Joint Committee of Infant Hearing $^{32}$

Data were collected at the Audiology and Electrophysiology Laboratory of the institution where the study was conducted. Procedures included an interview, visual inspection of the outer ear and acoustic immittance measurements.

Parents or guardians were interviewed to collect information regarding the hearing abilities, cognitive and language development, overall health and eligibility for assessment of the subjects.

The outer ear was examined using a Klinic Welch-Allyn brand otoscope, to identify any alterations or obstructions in the outer ear canal which would interfere with subsequent procedures.

Acoustic immittance measurements were conducted using an Interacoustics AT235 audiometer (Interacoustics, Middelfart, Denmark). The tympanometric curve and contralateral acoustic reflexes (at 500 to $4,000 \mathrm{~Hz}$ ) were investigated to identify any middle-ear alterations which would interfere with data collection. ${ }^{33}$

Subjects with no alterations in any examinations underwent an assessment of CAEPs, which were recorded and analyzed using the Smart EP platform. During the evaluation, subjects were comfortably seated on the laps of their guardians, watching a soundless video on a tablet PC, to ensure they sat still during data collection. After positioning the subject, the skin was cleaned using Nuprep abrasive gel (Weaver and Company, Aurora, CO, USA). Electrical signals were captured using MaxxFIX electrically conductive gel (Carbofix, Herzeliya, Israel) and electrodes were placed in the following locations: M1 and M2 (left and right mastoid, respectively), Cz (vertex) and Fpz (ground). Stimuli were presented through in-ear headphones, simultaneously to both ears, and consisted of the standard syllable $/ \mathrm{ba} /{ }^{26}$ at a fixed intensity of $70 \mathrm{dBnHL}$. Each subject was presented with a total of 300 stimuli. Only trials with $<10 \%$ artifacts were considered for analysis. Those with $>10 \%$ artifacts were excluded from the study.

To ensure the quality of the recordings, some subjects were asked to change positions to reduce myogenic interference. In some cases, for instance, subjects were asked to close their eyes to avoid ocular artifacts. ${ }^{34}$ To ensure the reliability of our findings, recordings were made in duplicate, and assessment sessions were rescheduled, if necessary.

Electrode impedance was $\leq 3 \mathrm{kOhms}$, with alternate polarity, and a 1 to $30 \mathrm{~Hz}$ passband filter with a $1,020 \mathrm{~ms}$ window. The responses to standard stimuli (the syllable/ba/), their latency in milliseconds (ms) and the P1-N1 and P2-N2 amplitudes in microvolts $(\mu \mathrm{V})$ were recorded. Amplitude was defined as the peak-to-trough distance, as recommended by the Smart EP 
product manual. The AEPs recordings were based on those described by Didoné et al. ${ }^{26}$ The study in question defined P1 as the highest peak between 50 and $200 \mathrm{~ms}$ after the onset of the stimulus, and $\mathrm{N} 1$ as the greatest negative deflection observed after P1. In relation to P2 and N2, the highest peak and deflection after the P1-N1 complex was considered.

All of the recordings were analyzed by two raters, both of whom were speech pathologists with practical and theoretical knowledge of electrophysiological methods, especially the assessment of CAEPs. Both raters were given copies of the recordings and asked to independently verify the latency and amplitude of P1, N1, P2 and N2. Raters were masked to participant groups to improve the reliability of the findings. The researchers later replicated these measurements using the IHS software (Intelligent Hearing Systems, SmartEP, Miami, Flórida, USA).

Considering the aforementioned eligibility criteria, the initial sample comprised 48 neonates who underwent cortical auditory evoked potentials (CAEPs). However, 29 newborns were excluded due to excess artifacts ( $>10 \%$ ) on CAEP recordings. As such, the final sample consisted of 19 subjects, 10 of whom were male while 9 were female.

Data were entered into a Microsoft Excel (Microsoft Corporantion, Redmond, WA, USA) spreadsheet for statistical analysis. Interrater agreement was evaluated using the Wilcoxon signed rank test and revealed no significant differences between the two sets of latency and amplitude ratings. The mean of the two ratings was therefore used in all subsequent analyses. The presence, latency (in $\mathrm{ms}$ ) and amplitude (in $\mu \mathrm{V}$ ) of each component of the CAEP was compared between ears and genders. Data were analyzed using the chi-squared, Wilcoxon and Mann-Whitney U tests. Results were considered significant at $p<0.05$. Confidence intervals (CIs) were calculated at the 95\% level.

\section{Results}

The first variable analyzed was the presence of each component of the CAEP in the sample. The presence of each component of the CAEP according to the gender and the ear of the subject is shown in - Table 1. The prevalence of P1 and N1 did not differ across the sample, since both were detected in all participants.

The comparison between the latency ( $\mathrm{ms}$ ) and amplitude $(\mu \mathrm{V})$ of components measured in either ear is shown in -Table 2. The sample size differed for P2 and N2 recordings, since these responses were only displayed by some of the participants.

No significant differences were identified between the left and right ears. The influence of gender on each component of the CAEP was analyzed by comparing the mean values of both ears for each participant (-Table 3). Only one component of the CAEP (P1) differed between genders; in the others, no statistically significant difference was observed.

\section{Discussion}

The development of the auditory cortex in the first year of life is marked by the emergence of neurofilaments in the upper layers of the auditory cortex, which are responsible for the emergence of the first components of the CAEP, such as the P1-N1 complex. ${ }^{7,21,23}$ Some researchers ${ }^{29}$ have suggested

Table 1 Analysis of the occurrence of components P1, N1, P2 and N2 of the cortical auditory evoked potential in the sample studied considering the variable genus, by ear $(n=19)$

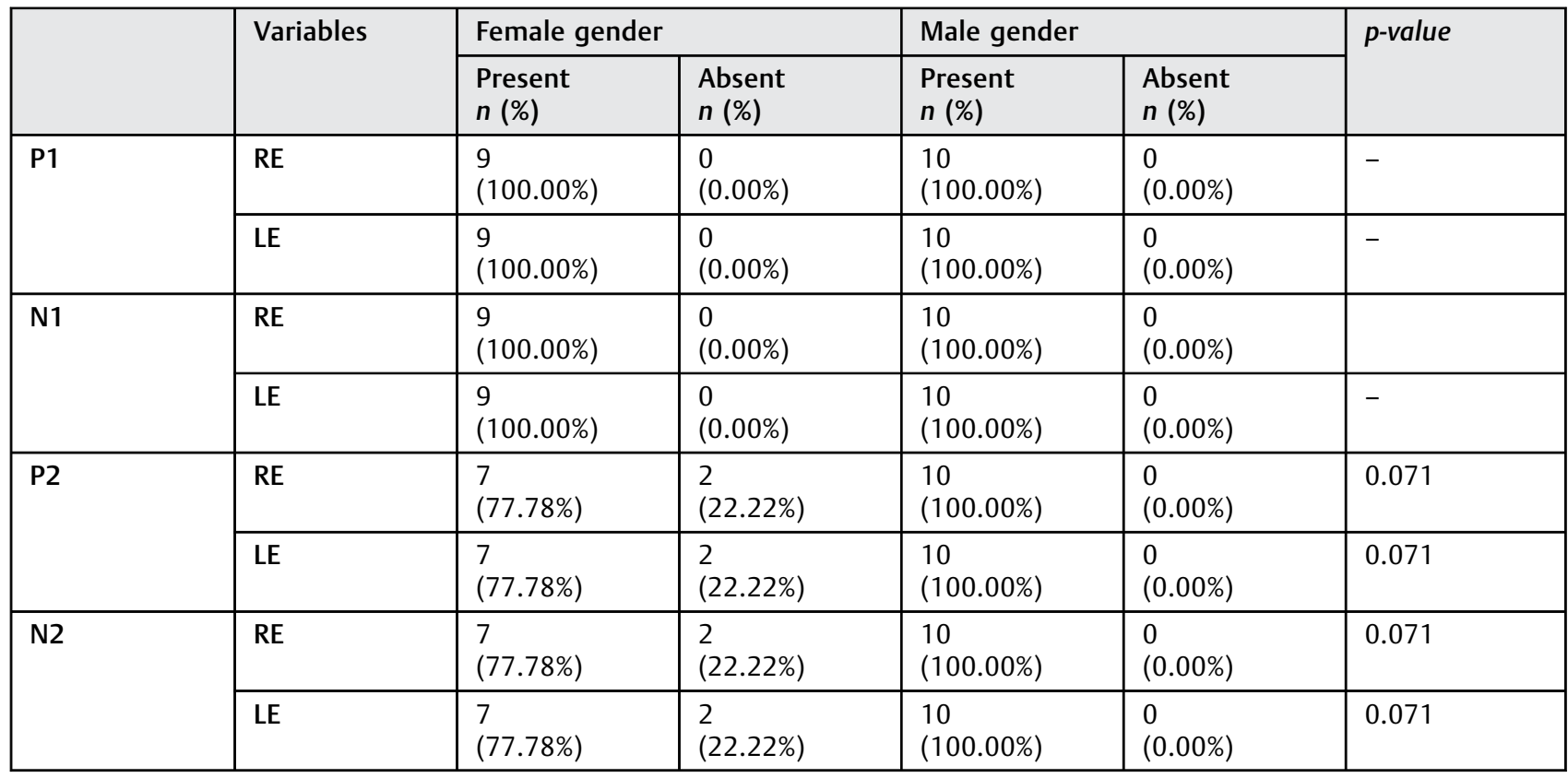

Abbreviations: LE, left ear; RE, right ear.

${ }^{*} \mathrm{p}$-value $\leq 0.05$ statistically significant; $\mathrm{n}=$ sample number. $\%=$ Percentage. Chi-squared test. 
Table 2 Comparison of the latency $(\mathrm{ms})$ and amplitude $(\mu \mathrm{V})$ of different components of the cortical auditory evoked potential detected in the right and left ear

\begin{tabular}{|c|c|c|c|c|c|c|c|c|}
\hline & & $n$ & Mean & Median & SD & Q1 & Q3 & $p$-value \\
\hline \multicolumn{9}{|c|}{$\begin{array}{l}\text { Latency } \\
\text { (ms) }\end{array}$} \\
\hline \multirow[t]{2}{*}{ P1 } & RE & 19 & 124.736 & 122.000 & 20.711 & 104.000 & 136.000 & \multirow[t]{2}{*}{0.434} \\
\hline & LE & 19 & 127.684 & 132.000 & 18.248 & 114.000 & 144.000 & \\
\hline \multirow[t]{2}{*}{ N1 } & RE & 19 & 237.157 & 236.000 & 44.792 & 216.000 & 268.000 & \multirow[t]{2}{*}{0.924} \\
\hline & $\mathrm{LE}$ & 19 & 236.631 & 236.000 & 40.293 & 210.000 & 260.000 & \\
\hline \multirow[t]{2}{*}{ P2 } & RE & 17 & 388.823 & 386.000 & 86.470 & 321.000 & 425.000 & \multirow[t]{2}{*}{0.831} \\
\hline & $\mathrm{LE}$ & 17 & 388.411 & 382.000 & 75.317 & 332.000 & 425.000 & \\
\hline \multirow[t]{2}{*}{ N2 } & RE & 17 & 472.647 & 452.000 & 110.525 & 428.000 & 540.000 & \multirow[t]{2}{*}{0.624} \\
\hline & LE & 17 & 474.058 & 453.000 & 100.441 & 416.000 & 558.000 & \\
\hline \multicolumn{9}{|c|}{$\begin{array}{l}\text { Amplitude } \\
(\mu \mathrm{V})\end{array}$} \\
\hline \multirow[t]{2}{*}{ P1N1 } & RE & 19 & 6.735 & 6.640 & 2.665 & 4.520 & 8.980 & \multirow[t]{2}{*}{0.903} \\
\hline & $\mathrm{LE}$ & 19 & 6.943 & 7.010 & 2.127 & 5.570 & 8.840 & \\
\hline \multirow[t]{2}{*}{$\mathrm{P} 2 \mathrm{~N} 2$} & $\mathrm{RE}$ & 17 & 3.351 & 2.740 & 1.560 & 2.340 & 4.460 & \multirow[t]{2}{*}{0.407} \\
\hline & LE & 17 & 3.161 & 2.970 & 0.995 & 2.410 & 3.430 & \\
\hline
\end{tabular}

Abbreviations: LE, left ear; RE, right ear; SD, Standard deviation.

"statistically significant at $p<0.05$. Wilcoxon test.

that there is a critical period for the maturation of the neural regions that generate the CAEP at $\sim 8$ to 12 months old, since this response undergoes significant changes at this age. Studies have found that while the P1 component can be recorded in all children, the $\mathrm{P} 2$ response can only be reliably detected at $\sim 2$ years old. Additionally, chronological age has been found to be the most influential variable in the devel-

Table 3 Gender comparisons of the latency (ms) and amplitude $(\mu \mathrm{V})$ of the $\mathrm{P} 1, \mathrm{~N} 1, \mathrm{P} 2$, and N2 components of the cortical auditory evoked potential $(n=19)$

\begin{tabular}{|c|c|c|c|}
\hline \multirow[t]{2}{*}{ Variables } & $\begin{array}{l}\text { Female gender } \\
(n=09)\end{array}$ & $\begin{array}{l}\text { Male gender } \\
(n=10)\end{array}$ & \multirow[t]{2}{*}{ p-value } \\
\hline & Mean \pm SD & Mean \pm SD & \\
\hline \multicolumn{4}{|l|}{$\begin{array}{l}\text { Latency } \\
\text { (ms) }\end{array}$} \\
\hline P1 & $118.22 \pm 21.50$ & $136.20 \pm 9.21$ & $0.034^{*}$ \\
\hline N1 & $237.33 \pm 40.97$ & $236.00 \pm 41.87$ & 0.660 \\
\hline $\mathrm{P} 2$ & $380.00 \pm 52.46$ & $390.40 \pm 90.14$ & 0.965 \\
\hline $\mathrm{N} 2$ & $474.00 \pm 74.51$ & $483.40 \pm 101.86$ & 0.859 \\
\hline \multicolumn{4}{|l|}{$\begin{array}{l}\text { Amplitude } \\
(\mu \mathrm{V})\end{array}$} \\
\hline P1N1 & $6.84 \pm 1.62$ & $7.02 \pm 2.58$ & 0.904 \\
\hline $\mathrm{P} 2 \mathrm{~N} 2$ & $3.26 \pm 1.29$ & $3.27 \pm 0.91$ & 0.678 \\
\hline
\end{tabular}

Abbreviations: ms, milliseconds; $\mu \mathrm{V}$, microvolts; $\mathrm{n}$, sample size; $\mathrm{SD}$, Standard deviation.

$p$ value for. Mann-Whitney $U$ test.

"statistically significant at $p<0.05$. opment of auditory pathways, since the latency of CAEP components appear to decrease in direct proportion to the age of the subject ${ }^{4,5,7,8,27}$.

As shown in - Table 1, all 19 participants in the present study displayed the P1/N1 components, while 17 displayed the $\mathrm{P} 2 / \mathrm{N} 2$ component at 2 years old. These findings support the idea of a critical period for the maturation of auditory pathways during the first years of life. These results also confirm our initial hypothesis, since all components of the CAEP could be detected at 2 years old. These conclusions agree with the previously cited studies. ${ }^{5,7,8,11,12,21,24,29}$ The absence of the P2/N2 complex ${ }^{20,23}$ in some participants may be attributed to individual variations in development, intrinsic to each subject, as well as by exposure to auditory stimuli in the first years of life, related to daily life situations, such as exposure to music, and interaction between family and the subject. $^{17}$

Another important point concerns the auditory abilities involved in generating these potentials. It is known that P2 is related to discrimination skills, while $\mathrm{N} 2$ involves attention. ${ }^{1,2,4}$ Thus, it is noted that the absence of P2 and N2 in some infants may be a maturational problem, but another hypothesis may be the use of a syllable as an acoustic stimulus. Perhaps such a stimulus is not interesting to evidence such components. Authors refer to what words evoked significantly larger CAEPs in newborns compared with responses evoked by tones, but in other age groups the effects of stimulus type on component amplitudes and latencies were less consistent. ${ }^{16}$

The present findings also showed that the presence, latency and amplitude of CAEP components did not 
significantly differ between the right and left ear, corroborating the hypothesis that central auditory skills develop synchronously in the left and right ear, as suggested by previous studies. ${ }^{18,30}$ These results also support the idea that auditory stimuli are processed bilaterally, and evoke similar responses in the central nervous system regardless of the ear which first detects it, as discussed by previous studies. $^{14,18,28-30}$

As can be seen in -Table $\mathbf{3}$, only one component of the CAEP (P1) differed between genders. The literature suggests that the latency of LLAEP components is similar between males and females; $8,25,28,31$ however, more studies comparing genders in the pediatric population are suggested for such finding to have clinical and / or scientific relevance. Therefore, in the present sample, we conclude that the maturation of auditory pathways was similar between ears and genders.

Authors report that gender differences that exist in the auditory system may interact with peripheral and hemispheric asymmetry for processing the sound. Otoacoustic emissions, click- and tone-evoked auditory responses and frequency following response (FFR) show differences between the genders. The authors hypothesized that in the FFR that difference would also exist, with females having faster and larger responses than males, and that these differences would be restricted to the encoding of the rapid features of the syllable speech such as the onset of the burst and formant noise-related frequencies. ${ }^{35}$

These findings have similarities only to the findings of the present study with respect to $\mathrm{P} 1$, perhaps because this component is a response from an area closer to the area responsible for FFR.

The latency of CAEP components, summarized in - Tables 2 and 3, has also been investigated in a previous study which sought to calculate the average interval for the latency of these potentials in subjects aged between 6 and 48 months old. The authors of the study in question reported an interval of 150 to $190 \mathrm{~ms}$ for P1; 210 to $260 \mathrm{~ms}$ for $\mathrm{N} 1 ; 260$ to $331 \mathrm{~ms}$ for P2; and 250 to $450 \mathrm{~ms}$ for N2. ${ }^{9}$ In a separate study, ${ }^{23}$ the mean latency and amplitude of P1 and N1 components in subjects aged between 3 and 8 months old was analyzed for verbal stimuli of different intensities. In the present study, the P1/N1 complex was detected in all participants. The mean latency of the P1 wave was between 150 and $200 \mathrm{~ms}$, while that of the $\mathrm{N} 1$ component was between 250 and $300 \mathrm{~ms}$. Other authors ${ }^{20}$ also analyzed CAEPs in response to stimuli of varying intensity ( $30 \mathrm{dBnHL}$ to $60 \mathrm{dBnHL}$ ) in subjects aged between 4 and 12 months old and found that the P2-N2 component was present in $87 \%$ of the sample. The mean latency for stimuli presented at $60 \mathrm{dBnHL}$ was $132 \mathrm{~ms}$ for P1, $215.70 \mathrm{~ms}$ for N1, $333.08 \mathrm{~ms}$ for P2 and $461.67 \mathrm{~ms}$ for N2.

Some studies ${ }^{21,23}$ have also found that the intensity and acoustic characteristics of the stimulus have a significant influence on the latency and amplitude of CAEP components. These investigations have found that stimulus intensity is directly related to the amplitude and inversely related to the latency of AEPs.
Reference values for the latency and amplitude of CAEP components have been established by previous studies of pediatric populations. 4,8,9,18,20,21,23 However, these values differ between studies, possibly due to variations in the recording equipment used, the type of data analysis, and the characteristics of the samples studied.

\section{Conclusion}

In the present study, in addition to the P1/N1 components, it was possible to observe the presence of the CAEP P2/N2 components in individuals aged 24 months old, confirming the existence of a critical period for the maturation of the auditory pathways in the first 2 years of life.

Conflict of Interests

The authors have no conflict of interests to declare.

\section{References}

1 McPherson DL. Late potentials of the auditory system. San Diego: Publishing Group; 1996

2 Paulraj MP, Subramaniam K, Yaccob SB, Adom AHB, Hema CR. Auditory evoked potential response and hearing loss: a review. Open Biomed Eng J 2015;9:17-24

3 Picton TW, Woods DL, Baribeau-Braun J, Healey TMG. Evoked potential audiometry. J Otolaryngol 1976;6(02):90-119

4 Silva LAF, Couto MIV, Tsuji RK, Bento RF, Matas CG, Carvalho ACM. Auditory pathways' maturation after cochlear implant via cortical auditory evoked potentials. Rev Bras Otorrinolaringol (Engl Ed) 2014;80(02):131-137

5 Silva LAF, Magliaro FCL, Carvalho ACM, Matas CG. Maturação dos potenciais evocados auditivos de longa latência em crianças ouvintes: revisão sistemática. CoDAS 2017;29(03):e20160107. Doi: 10.1590/2317-1782/20172016107

6 Silva LAF, Couto MIV, Magliaro FCL, et al. Cortical maturation in children with cochlear implants: Correlation between electrophysiological and behavioral measurement. PLoS One 2017;12:171-177

7 Sharma A, Campbell J, Cardon G. Developmental and cross-modal plasticity in deafness: evidence from the $\mathrm{P} 1$ and $\mathrm{N} 1$ event related potentials in cochlear implanted children. Int J Psychophysiol 2015;95(02):135-144. Doi: 10.1016/j.ijpsycho.2014.04.007

8 Alvarenga KF, Vicente LC, Lopes RCF, Ventura LMP, Bevilacqua MC, Moret ALM. Desenvolvimento do potencial evocado auditivo cortical P1 em crianças com perda auditiva sensorioneural após o implante coclear: estudo longitudinal. CoDAS 2013; 25:521-526. Doi: 10.1590/S2317-17822014000100004

9 Choudhury N, Benasich AA. Maturation of auditory evoked potentials from 6 to 48 months: prediction to 3 and 4 year language and cognitive abilities. Clin Neurophysiol 2011;122 (02):320-338. Doi: 10.1016/j.clinph.2010.05.035

10 Maitre NL, Lambert WE, Aschner JL, Key AP. Cortical speech sound differentiation in the neonatal intensive care unit predicts cognitive and language development in the first 2 years of life. Dev Med Child Neurol 2013;55(09):834-839

11 Scheerer NE, Liu H, Jones JA. The developmental trajectory of vocal and event-related potential responses to frequency-altered auditory feedback. Eur J Neurosci 2013;38(08):3189-3200. Doi: 10.1111/ejn.12301

12 Costa LD, Quinto SMS, Didoné DD, Rechia IC, Garcia MV, Biaggio EPV. Audição e linguagem em crianças nascidas a termo e prétermo. Audiol Commun Res 2016;21:1-7. Doi: 10.1590/23176431-2016-1672

13 Sharma A, Kraus N, McGee TJ, Nicol TG. Developmental changes in $\mathrm{P} 1$ and $\mathrm{N} 1$ central auditory responses elicited by consonant-vowel 
syllables. Electroencephalogr Clin Neurophysiol 1997;104(06): 540-545. Doi: 10.1016/S0168-5597(97)00050-6

14 Melo Â, Biaggio EPV, Rechia IC, Sleifer P. Cortical auditory evoked potentials in full-term and preterm neonates. CoDAS 2016;28 (05):491-496

15 Rechia IC, Fattore IM, Moraes AB, Biaggio EPV, Souza APR. Auditory maturation and psychological risk in the first year of life. CoDAS 2018;30(04):e20170142. Doi: 10.1590/2317-1782/ 20182017142

16 Wunderlich JL, Cone-Wesson BK, Shepherd R. Maturation of the cortical auditory evoked potential in infants and young children. Hear Res 2006;212(1-2):185-202

17 Northern JL, Downs MP. Audição na Infância. $5^{\circ}$ ed. Rio de Janeiro: Guanabara Koogan; 2005

18 Alvarenga KF, Amorim RB, Agostinho-Pesse RS, Costa OA, Nascimento LT, Bevilacqua MC. Speech perception and cortical auditory evoked potentials in cochlear implant users with auditory neuropathy spectrum disorders. Int J Pediatr Otorhinolaryngol 2012; 76(09):1332-1338

19 Almeida RP, Matas CG. Long latency auditory evoked potentials in malnourished children. CoDAS 2013;25(05):407-412

20 Cardon G, Sharma A. Central auditory maturation and behavioral outcome in children with auditory neuropathy spectrum disorder who use cochlear implants. Int J Audiol 2013;52(09):577-586. Doi: 10.3109/14992027.2013.799786

21 Cone B, Whitaker R. Dynamics of infant cortical auditory evoked potentials (CAEPs) for tone and speech tokens. Int J Pediatr Otorhinolaryngol 2013;77(07):1162-1173

22 Oliveira JC, Murphy CFB, Schochat E. Auditory processing in children with dyslexia: electrophysiological and behavior evaluation. CoDAS 2013;25(01):39-44

23 Purdy SC, Sharma M, Munro KJ, Morgan CLA. Stimulus level effects on speech-evoked obligatory cortical auditory evoked potentials in infants with normal hearing. Clin Neurophysiol 2013;124(03): 474-480

24 Silva LA, Couto MI, Matas CG, Carvalho AC. Potenciais evocados auditivos de longa latência em crianças com implante coclear: revisão sistemática. CoDAS 2013;25(06):595-600
25 Agostinho-Pesse RS, Alvarenga KF. Late auditory evoked potentials to speech stimuli presented with different transducers in hearing children. Rev CEFAC 2014;4:13-22

26 Didoné DD, Garcia MV, da Silveira AF. Long latency auditory evoked potential in term and premature infants. Int Arch Otorhinolaryngol 2014;18(01):16-20

27 Figueiredo SR, Lewis DR. Potenciais evocados auditivos corticais em crianças com perda auditiva: estudo piloto. Distúrb Comun 2014;26:622-623

28 Reis ACMB, Frizzo ACF, Lozano AC, Santos FRD, Anastasio ART, Hyppolito MA. Variability of registration latency and amplitude of the auditory evoked potential long latency (P3) in the condition test and retest. Audiol Commun Res 2014;19: 293-298

29 Shafer VL, Yu YH, Wagner M. Maturation of cortical auditory evoked potentials (CAEPs) to speech recorded from frontocentral and temporal sites: three months to eight years of age. Int J Psychophysiol 2015;95(02):77-93. Doi: 10.1016/j.jpsycho.2014.08.1390

30 Oppitz SJ, Didoné DD, Silva DD, et al. Long-latency auditory evoked potentials with verbal and nonverbal stimuli. Rev Bras Otorrinolaringol (Engl Ed) 2015;81(06):647-652

31 Simões HdeO, Frizzo ACF, Zanchetta S, Hyppolito MÂ, Reis ACMB. Variables in P300 recording: task type and electrode position. CoDAS 2016;28(04):355-361

32 American Academy of Pediatrics, Joint Committee on Infant Hearing. Year 2007 position statement: Principles and guidelines for early hearing detection and intervention programs. Pediatrics 2007;120(04):898-921

33 Jerger J, Jerger S, Mauldin L. Studies in impedance audiometry. I. Normal and sensorineural ears. Arch Otolaryngol 1972;96(06): 513-523

34 Regaçone SF, Gução ACB, Giacheti CM, Romero ACL, Frizzo ACF. Potenciais evocados auditivos de longa latência em escolares com transtornos específicos de aprendizagem. Audiol Commun Res 2014;19:13-18

35 Krizman J, Skoe E, Kraus N. Sex differences in auditory subcortical function. Clin Neurophysiol 2012;123(03):590-597. Doi: 10.1016/j.clinph.2011.07.037 